\title{
THE UTILIZATION OF VARIOUS ASCLEPIAS SPECIES BY LARVAE OF THE MONARCH BUTTERFLY, DANAUS PLEXIPPUS
}

\author{
By James M. Erickson* \\ Dept. of Entomology, Cornell University \\ Ithaca, New York, I4850
}

\section{INTRODUCTION}

Plants of the genus Asclepias are well known to contain high concentrations of cardiac glycosides (cardenolides). It is generally surmised that such cardiac stimulants function to protect plants containing them against insect and vertebrate herbivores (Euw et al. 1967). In addition, some insects which are adapted to feed on Asclepias plants store cardiac glycosides apparently as a means of protection against vertebrate predators which find the compounds distasteful (Brower and Brower 1964, Brower 1969). It was by means of such an herbivore-predator interaction, bluejays feeding on monarch butterflies, Danaus plexippus L. (Brower 1969, Brower et al. 1968), that a spectrum of palatability was detected among monarch butterflies reared on various species of milkweed. It is surmised that this spectrum of toxicity to a vertebrate predator reflects a spectrum of concentrations of cardiac glycosides in the different species of the insects' larval food plants (Brower and Brower I964, Brower et al. 1967, Brower 1969). However, quantitative and qualitative data for cardenolides in Asclepias leaves are at best incomplete (Reynard and Morton 1942, Kupchan et al. 1964, Duffey 1970, Singh and Rastogi 1970, Feir and Suen 1971, Duffey and Scudder 1972, Scudder and Duffey 1972, and Eggermann and Bongers 1972).

The following experiments were undertaken to determine whether a differential response by $D$. plexippus larvae to their host plants could be detected by measuring their efficiency of food utilization and whether such a response would support the concept of a spectrum of toxicity. It seemed conceivable that detoxication or storage of cardiac glycosides might require expenditure of energy and could be detected by a lowered feeding efficiency. In addition, Brower et al. (1972) have speculated that there is a reduction in

\footnotetext{
*Present address: Dept. of Biological Sciences, California State University, Hayward, California 94542.

Manuscript received by the editor June 18, 1973.
} 
general viability of monarch adults which have stored higher concentrations of cardiac glycosides. To test this hypothesis the fertility and fecundity of adult monarchs was determined.

\section{Methods AND Materials}

Groups of intact larvae of $D$. plexippus ${ }^{1}$ were taken from the second generation of a culture founded from wild insects taken near Ithaca, New York, and were reared in the laboratory on one of the following species of $A$ sclepias $^{1}$ host plants: $A$. curassavica, $A$. syriaca, $A$. incarnata, or $A$. tuberosa. Newly molted 4th-instar larvae were placed individually in glass petri dishes (Pyrex, Ioomm $\times$ I $5 \mathrm{~mm}$ ) lined on the bottom with a piece of Whatman No. I filter paper. Mature and uninjured leaves of the native species were gathered in the field each day from plants growing in open sunlit areas, and leaves of $A$. curassavica were collected from plants grown in the greenhouse. All leaves were sealed in plastic bags and used within 2 hours. These randomly collected leaves were split along the midrib, one half weighed and offered to the larvae and the other half used to determine the percent dry matter in the leaf material (Waldbauer 1960, I964). Leaves were replaced and feces collected every 24 hours.

All the larvae were placed in a controlled temperature room, except for the period of time each day during which new food was offered to the larvae and the feces collected. The room was kept relatively constant with day-night temperatures of $22^{\circ}$ and $18^{\circ}$, respectively, and with a relative humidity of approximately $55 \%$. The photoperiod was regulated at a $16-8$ hour light-dark cycle.

The dry weight of food ingested was estimated following the techniques of Waldbauer (1960, I964), except that plant material was lyophilized instead of oven-dried. The dry weight of the food utilized or assimilated was assumed to be the dry weight of the food ingested minus the dry weight of feces. An additional group of larvae was reared along with the experimental larvae, and these were sacrificed to determine the dry weights, and thus, the percentage dry matter of the larvae. Indices of food utilization were determined following the methods of Waldbauer ( I960, I964, 1968). Many terms have been used both by ecologists and by physiologists to describe various measures and indices of food

\footnotetext{
${ }^{1}$ Specimens of the insects used in this research have been deposited in the Cornell University Insect Collection, Lot 1023, Sublot 14. Specimens of the plants have been deposited in the Bailey Hortorium, Cornell University.
} 
utilization and efficiency. Relationships between many of these terms are discussed by Kozlovsky (1968) and Waldbauer (1968).

As an index of digestibility the ratio of the amount of food assimilated to the amount of food ingested, referred to as the 'Assimilation Efficiency' (Odum, 197I) or the 'Coefficient of Digestibility' (Waldbauer 1964, I968, House 1965), was used. In practice, this measure is only an approximation since the numerator (as determined by the standard gravimetric technique) does not quite represent the amount of food actually assimilated (Waldbauer 1968). This slight error is due to the presence of metabolic wastes in the feces in addition to the undigested food (Lafon 195I), but Hiratsuka (1920) and Waldbauer (1964, 1968) point out that this difference between true and measured assimilation efficiencies is negligible.

The efficiency with which ingested food is converted to biomass is calculated by dividing the dry weight of food ingested into the dry weight gained by the larva. This index, referred to by physiologists as the 'Efficiency of Conversion of Ingested Matter' (Waldbauer 1968) and by ecologists as the 'Ecological Growth Efficiency' (Odum 197I), is an overall measure of an animal's ability to utilize for growth the food ingested.

The efficiency with which digested food is converted to biomass is calculated by dividing the dry weight of food assimilated into the dry weight gained by the larva. This index, referred to by Waldbauer (1968) as the 'Efficiency of Conversion of Digested Matter' and by Odum (197I) as the 'Tissue Growth Efficiency', decreases as the proportion of digested food metabolized for energy and maintenance of physiological functions increases (Waldbauer 1968).

The relative growth rate is calculated by dividing the mean dry weight of the larva times the duration of the instar in days into the dry weight gained by the larva during the stadium (Waldbauer 1968). This index reflects the rate at which biomass is added by a larva corrected for any size differential between groups of larvae.

The 'Respiratory Coefficient' (Lindeman 1942) is described as the ratio of respiratory and maintenance loss to the net secondary production or biomass increase. This coefficient is calculated by dividing the total calories lost through respiration and maintenance by the total calories added to the insects' biomass. This ratio is what may be termed an 'Energy Production Cost Ratio'; the smaller the coefficient or ratio, the more efficient the larva is at allocating energy to biomass, the larger the coefficient, the greater the number 
of calories lost through respiration and maintenance per calorie allocated to biomass.

Of general interest to ecologists is the 'Principle of Allocation' described by Cody (1966). Organisms have a limited amount of energy to spend and will be selected to partition this energy in different ways depending upon changing physiological or environmental conditions. Any activity of an organism, or more precisely, the energy expenditure for that activity, can be viewed only in relation to all other demands for energy. To descry any increased 'cost' of detoxifying or incorporating cardenolides by $D$. plexippus larvae when reared on Asclepias host plants with known toxicity spectrum, a larval energy budget based on dry weights was constructed. Calorific values of the larval food plants, feces and larvae were determined by means of a Phillipson non-adiabatic microbomb calorimeter (Gentry and Wiegert Inst. Inc., Aiken, C.S.) (Phillipson 1964). The lyophilized plant material was subjected to five replications whereas lyophilized larvae and feces were subjected to three replications for the determination of calorific values.

The nitrogen content of the leaf material was determined by the Kjeldahl method for total nitrogen (Williams i964). A minimum of three replicate samples were obtained for each of the plant species.

For the purposes of food utilization and efficiency determinations, the experiment was concluded when the larvae molted into the ultimate instar. The larvae were then reared through to the adult stage on the same experimental plants that they fed upon in the utilization experiments. All adult females were hand paired and placed individually in a $\mathrm{I}$ meter square screen cage with one $A$. curassavica and one $A$. syriaca plant of approximately the same age and condition. Records were kept each day of the number of eggs layed per female and the percentage of these eggs which were fertile.

The data are generally presented as a mean and standard error for the larvae in any particular treatment group. The various experimental parameters and indices were subjected to one-way analysis of variance to determine differences in efficiencies or developmental rates among the various larval food plants.

\section{Results}

Various plant parameters differed greatly among the four Asclepias species offered to the monarch larvae (Table I). The leaves of $A$. tuberosa were significantly higher in dry matter content than the other three species. No significant difference in caloric content could 


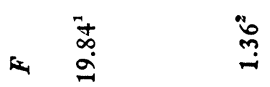

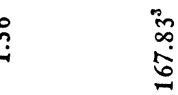

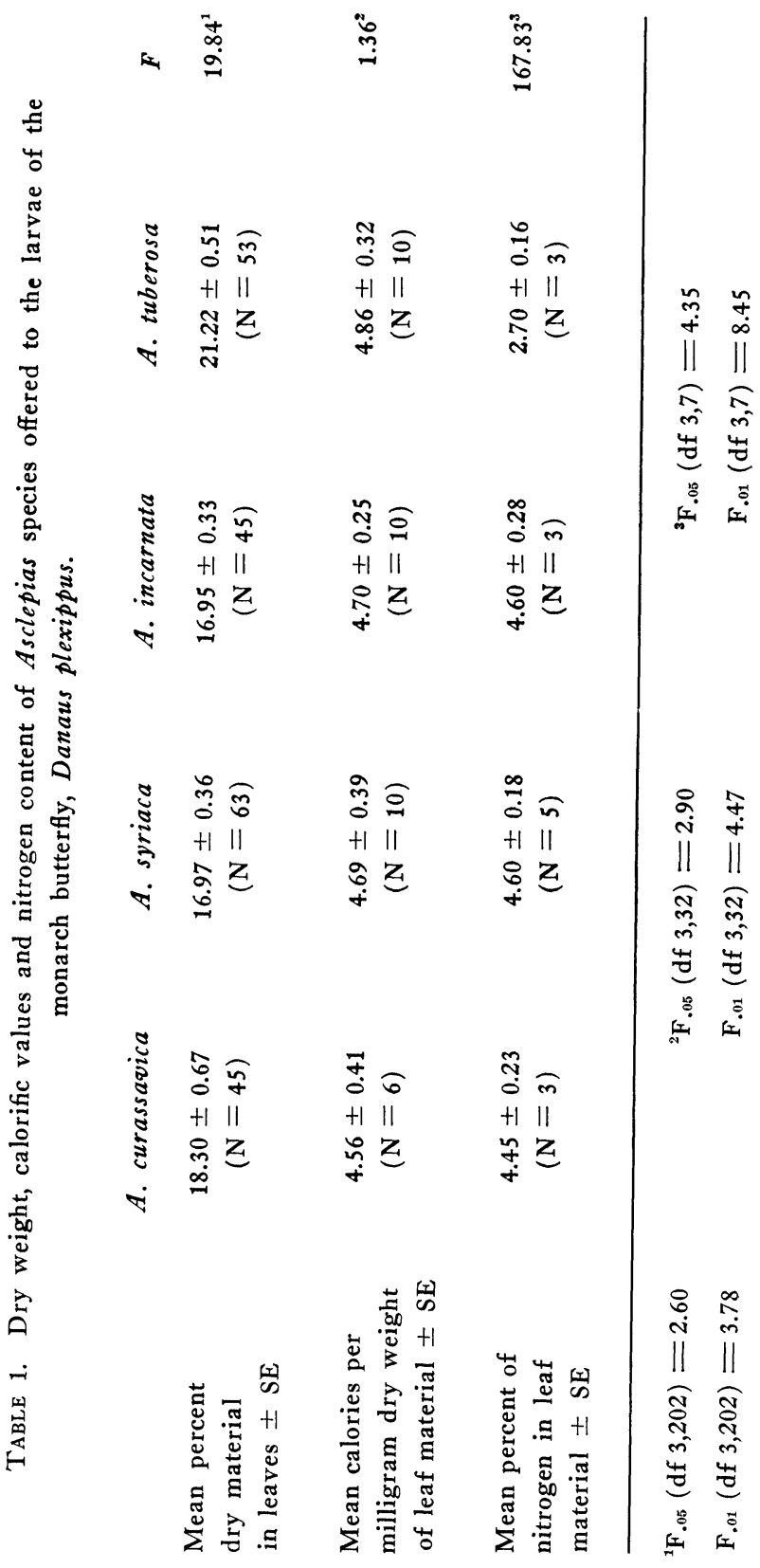


be found among the four Asclepias species. The nitrogen content of the leaf material did not vary significantly for $A$. curassavica, $A$. syriaca, and $A$. incarnata but the leaves of $A$. tuberosa contained a little more than one half the total nitrogen content of the other plants examined.

The proportion of ingested food which was digested and assimilated ('assimilation efficiency') averaged about 50\% for all experimental host plants except for $A$. syriaca which was significantly higher $(\mathrm{P}<0.05)$ with a mean of approximately $58 \%$ (Table 2). The efficiency with which ingested matter was converted to biomass ranged from $29.59 \%$ for larvae reared on $A$. syriaca to $\mathrm{I} 6.39 \%$ for larvae reared on $A$. tuberosa $(\mathrm{P}<\mathrm{O} . \mathrm{OI})$, whereas the efficiency of conversion of digested matter ranged from $53.30 \%$ for larvae reared on $A$. curassavica to $34.04 \%$ for larvae reared on $A$. tuberosa ( $\mathrm{P}<\mathrm{O} . \mathrm{OI})$. The duration of the 4 th stadium also varied significantly $(\mathrm{P}<\mathrm{O} . \mathrm{OI})$ with larvae on $A$. curassavica having the shortest duration (2.15 days) and larvae on $A$. syriaca having the longest duration ( 2.55 days). The amount of biomass gained per day per larva also varied significantly $(\mathrm{P}<0.05)$ with larvae reared on $A$. curassarica gaining the most weight ( 6.42 $\mathrm{mg} /$ day) and larvae on $A$. incarnata the least (I2.70 $\mathrm{mg} /$ day). Of great interest, however, is that the relative growth rate did not vary significantly for the larvae feeding on the four Asclepias species.

The total allocation of energy by the larvae on the different host plants can be found in Table 3. The larvae reared on $A$. tubenosa ingested and assimilated almost twice as many calories as larvae reared on $A$. curassavica or $A$. syriaca. The total number of calories allocated to larval biomass did not vary to any extent among the Asclepias species; ingestion of more calories by larvae reared on $A$. incarnata and $A$. tuberosa was balanced by greater costs for respiration and maintenance. The ratio of the total number of calories. allocated to an increase in larval biomass to the total calories assimilated ranged from approximately $65 \%$ by larvae reared on $A$. curassavica to approximately $32 \%$ for larvae reared on $A$. tuberosa. The respiratory coefficient also ranged from 0.53 ( $A$. curassavica) to 2.16 ( $A$. tuberosa).

There was no difference in the mean length of the larval stage or the pupal stage among larvae reared on the various Asclepias species (Table 4). Larval survival was $100 \%$ on all host plants except $A$. incarnata where $90 \%$ of the larvae survived to the adult stage. Fecundity and fertility does not vary significantly; the mean number of eggs layed per female ranged from I03.7 for females reared on 


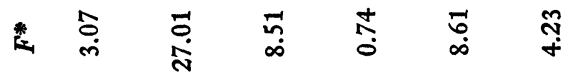

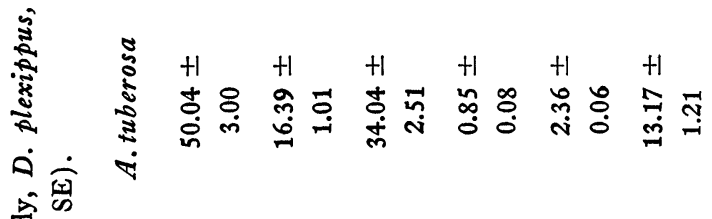

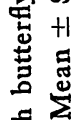

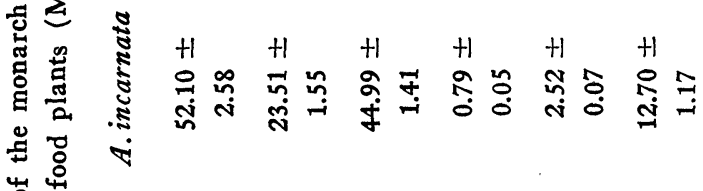

范

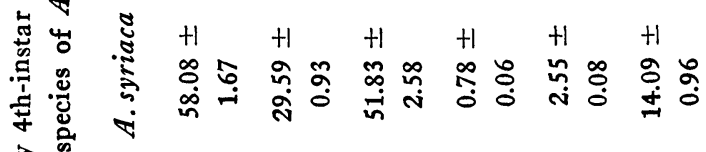

के

宽

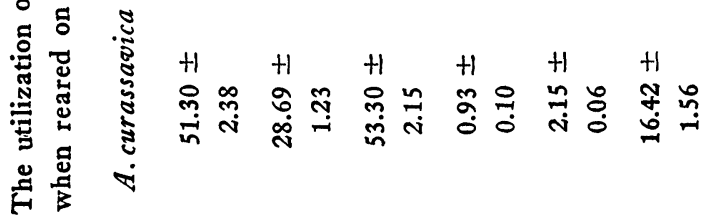

宊

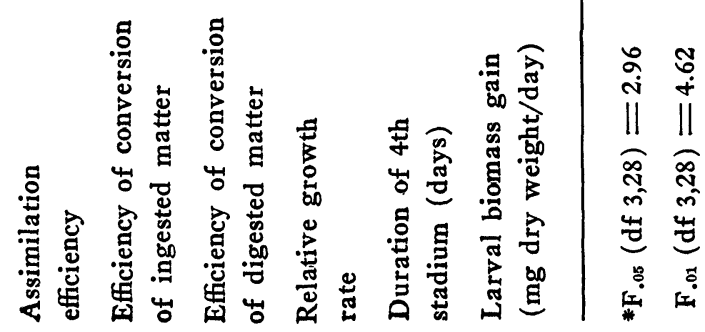


A. curassavica to II 7.2 for females reared on $A$. syriaca. The mean per cent of eggs hatching ranged from $87.3 \%(A$. incarnata $)$ to 93.2\% (A. tuberosa).

\section{Discussion}

One of the major concerns of modern ecology is the description and explanation of the energetic relationships between and within various communities. A knowledge of the food utilization efficiency of insects is thus of particular importance to ecology since insects exert a substantial influence and impact on almost all terrestrial or fresh water communities. The ecological significance of such energy utilization studies have been extensively reviewed (Englemann 1966, Phillipson 1966, and others).

It seems apparent that adaptive nutritional differences in host plants must be sought on a quantitative level and that meaningful comparisons of food utilization and nutrition will not emerge until quantitative studies are carried out. The determination of absolute requirements for dietary constituents depends upon the measurement of food or nutrient intake. Differences in food efficiency can be demonstrated only be measuring intake and growth. Measurement of the food intake and the utilization of this food elucidates to a great degree the physiological processes occurring in an insect since patterns of utilization may be different although food sources are similar in their ability to support growth. For instance, low food intake may be offset by a high utilization of ingested or digested food and a very high food intake may well lead to a very low efficiency in the utilization of ingested or digested matter.

In this experiment, the assimilation efficiency of the larvae did not vary significantly among the various $A$ sclepias host plants except for larvae reared on $A$. syriaca which had an efficiency about $8 \%$ higher than larvae on the other host plants. This means that the larvae reared on the various host plants were digesting and excreting approximately equal amounts of food. The efficiency with which ingested food and digested food are utilized varied significantly with larvae reared on $A$. curassavica and $A$. syriaca having the highest efficiencies and larvae reared on $A$. tuberosa the lowest (Table 2). The efficiency with which digested food is utilized for growth will vary not only with the maintenance and respiration requirements for energy but also with the balance of nutrients in the food source. Larvae reared on $A$. tuberosa ingested almost twice as much food during the 4 th instar as larvae reared on the other three host plants 


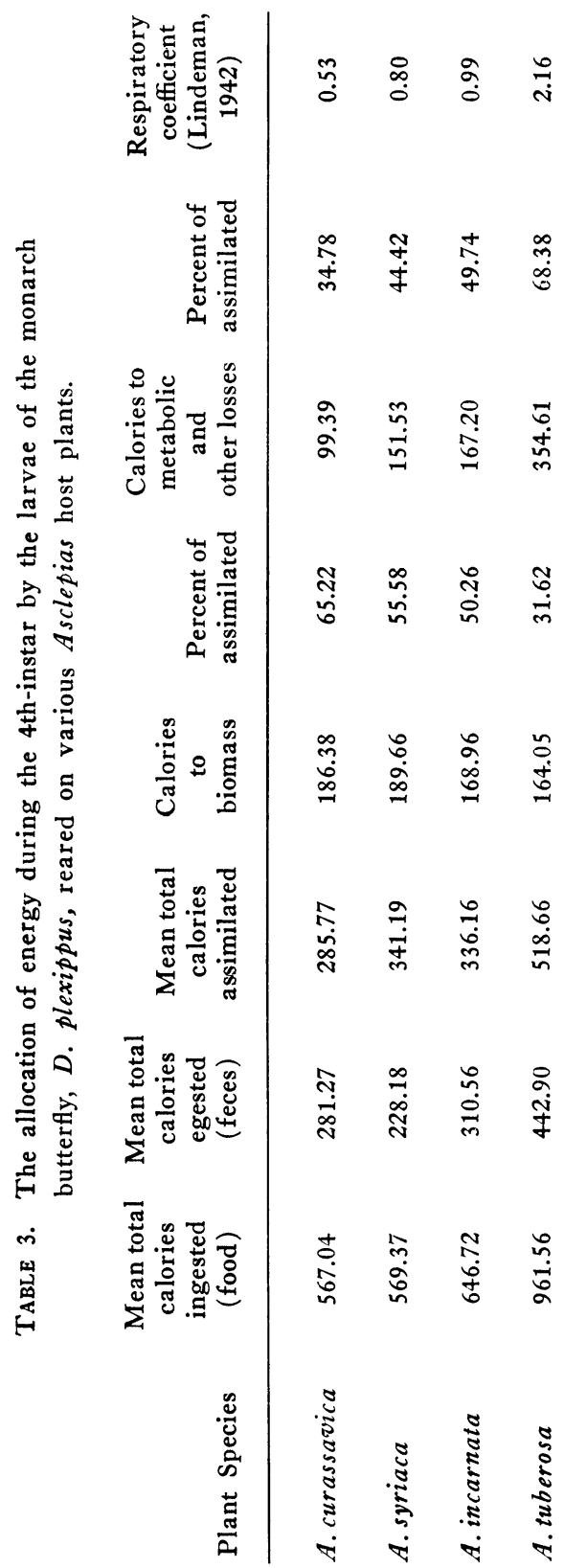


(see Table 3). As the ingestion rate increases, there is a negative correlation with the efficiency with which ingested or digested matter are utilized (Waldbauer I968). This reduction in overall gross and net efficiency has been shown for Prodenia larvae (Soo Hoo and Fraenkel 1966) and by House (1965). The larvae reared on $A$. tuberosa may be viewed as being extremely 'wasteful' of the potential caloric content of their food, most likely passing great quantities of food through the digestive tract to secure a supply of some limiting nutrient or substance. The leaf material does not vary to any significant degree among the Asclepias species tested in terms of caloric content (Table I), whereas the leaves of $A$. tuberosa contain a little more than one half the nitrogen content of the other three species.

It has been suggested that the water content of food material will greatly affect the utilization of this material. It is generally the case with the swallowtail butterfly, Papilio polyxenes, that the efficiency of utilization of food decreases as the dry matter content of the food plant increases (Erickson and Feeny, in preparation). In this experiment, there is a significant difference in the dry matter content of the leaves, with $A$. tuberosa having the highest dry matter content at approximately 21\% and $A$. incarnata and $A$. syriaca the lowest dry matter content at about $17 \%$ (Table I). It has been shown in this laboratory, that by varying the water content of leaf material, the utilization of food by the cecropia moth, Hyalophora cecropia is greatly affected (J. M. Scriber, in preparation). The effect is shown not in an increased intake rate, as occurs in monarch larvae, but in lengthened larval development times, in which the total food intake is increased but the rate of this intake remains relatively constant. It thus appears that the dry matter content of Asclepias leaves may have some influence on the utilization efficiencies but not to the degree found in this experiment.

In keeping with Cody's ( I966) 'Principle of Allocation', I attempted to descry any increased 'cost' for $D$. plexippus larvae to detoxify or to incorporate cardenolides. It is well known that $A$. curassavica is highty toxic and contains at least 15 cardenolidies (Kupchan et al. 1964, Duffey 1970), three of which have been isolated from distasteful D. plexippus larvae (Parsons 1965, Reichstein 1967) incorporated there as a defense against vertebrate predators (Brower and Brower 1964, Brower et al. 1967, Brower 1969). Asclepias syriaca has been found to be only slightly toxic to vertebrates and to contain at least seven cardiac glycosides (Reynard and Morton 1942, Duffey 1970, and others). Asclepias incarnata and A. tuberosa are known to contain cardenolides but in much lower 
TABLE 4. Length of pupation, fecundity and fertility of monarch butterflies raised on various plants of the genus Asclepias.

\begin{tabular}{lcccc} 
Host plant & $\begin{array}{c}\text { Number of } \\
\text { animals }\end{array}$ & $\begin{array}{c}\text { Mean length } \\
\text { of pution } \\
\text { (days) }\end{array}$ & $\begin{array}{c}\text { Mean total } \\
\text { number of eggs } \\
\text { per female } \\
\pm \mathrm{SE}^{12}\end{array}$ & $\begin{array}{c}\text { Mean percent } \\
\text { of eggs } \\
\text { hatching } \\
\pm \mathrm{SE}^{13}\end{array}$ \\
\hline $\begin{array}{l}\text { A. curassavica } \\
\text { A. syriaca }\end{array}$ & 12 & 10.31 & $105.7 \pm 8.7$ & $91.6 \pm 4.9$ \\
$\begin{array}{l}\text { A. } \text { incarnata } \\
\text { A.tuberosa }\end{array}$ & 12 & 10.67 & $117.2 \pm 10.6$ & $89.1 \pm 5.7$ \\
\hline
\end{tabular}

${ }^{1} \mathrm{~F}_{.05}(\mathrm{df} 3,20)=3.10$

$F_{.01}(\mathrm{df} 3,20)=4.94$

${ }^{2} \mathrm{~F}=1.13$

${ }^{3} \mathrm{~F}=0.73$

concentrations (Duffey 1970, Singh and Rastogi 1970) and only marginally toxic (Hansen 1924, Heal et al. 1950). It is found, however, that contrary to expected results, larvae reared on the highly toxic $A$. curassavica gained more biomass per day, spent the shortest time in the 4 th instar, and were the most efficient at utilizing and converting digested matter into biomass (Table 2). In addition, larvae reared on $A$. curassavica utilized approximately $65 \%$ of the assimilated energy to produce biomass whereas only $32 \%$ of the assimilated energy was allocated to biomass for larvae reared on $A$. tuberosa (Table 3), and larvae reared on $A$. curassavica had the lowest 'Respiratory Coefficient' at 0.53 compared to larvae reared on $A$. tuberosa which had a value of 2.I6. This means that larvae reared on the $A$. curassavica host plant were allocating about 2 calories for biomass for every calorie lost through respiration and maintenance, whereas larvae reared on $A$. tuberosa allocated approximately 0.5 calorie to biomass for every calorie lost through respiration and maintenance. It thus appears that there is little measurable 'cost' to detoxify or incorporate caridac glycosides by monarch larvae since the larvae grew and developed most rapidly on the most toxic Asclepias food plant tested. 
Recently, Brower et al. (I972) have shown a general decrease in cardiac glycoside content of migrating monarch butterflies as the specimens are collected farther south. They feel selection may be operating against high cardiac glycoside content (larvae reared on A. curassavica or $A$. humistrata) since, although high concentrations of cardiac glycosides in the butterfly confer greater protection from predators, these authors surmise that these high concentrations decrease the viability of the insect. In this experiment, there was no significant difference in either the number of eggs deposited or the number of these that were fertile among the adult females reared on the four Asclepias species (Table 4). It does not appear at least over a couple of generations, that larvae reared on $A$. curassavica are any less viable than larvae reared on much less toxic $A$ sclepias species.

The importance of nitrogen for larval growth and development cannot be overemphasized. House (1961, 1962) and Dadd (1973) have discussed the qualitative requirements of proteins and amino acids for larval development. There appears to be an optimal nitrogen level, which varies from species to species, that produces maximal larval growth (Dadd 196I, House 1959, Vanderzant 1958). The fecundity of Dacus dorsalis Hendel increased with an increase in the protein content of the diet (Hagen 1958), whereas low protein levels greatly prolonged the developmental period of Drosophila melanogaster (Sang 1956). In this experiment, larvae reared on A. tuberosa had the second fastest developmental time of the 4 groups of larvae, yet this plant species contained a little more than one half the nitrogen content in the leaves than was contained in the other leaves of the other host plants. Larvae of the monarch butterfly appear, therefore, to have an adaptive strategy which allows them to best utilize a resource that is in limited supply. Although 'wasteful' in the caloric sense, these larvae are able to secure the necessary supply of nitrogen needed for the later adult stage by increasing their total intake of food (Table 3). A similar situation has been demonstrated in this laboratory involving the utilization of crucifer plants by Pieris rapae (Slansky and Feeny, in preparation). This ability of an insect to compensate for decreased nutrient content of its food is discussed by House (1965) and McGinnis and Kasting (1966). It thus appears that the low nitrogen content of $A$. tuberosa has a somewhat limiting effect on the monarch larvae but this low nutrient content only limits or regulates the efficiency with which food is utilized by the larvae and does not limit the larval growth or consumption rates to a significant degree. 


\section{Acknowledgments}

The author wishes to thank Drs. L. P. Brower, P. P. Feeny and J. G. Franclemont for reading the manuscript and offering helpful suggestions. Many thanks also go to Ms. Sherry Rehr for technical help and also offering suggestions on the manuscript. The work was supported in part by Hatch Grant NY (C) I39413 of Dr. Paul Feeny.

\section{Literature Cited}

BROWER, L. P.

1969. Ecological chemistry. Sci. Amer. $220: 22-29$.

Brower, L. P., and J. V. Z. Brower.

1964. Birds, butterflies, and plant poisons: A study of ecological chemistry. Zoologica 49: 137-159.

Brower, L. P., J. V. Z. Brower, and J. M. Corvino.

1967. Plant poisons in a terrestrial food chain. Proc. Nat. Acad. Sci. 57: 893-898.

Brower, L. P., W. N. Ryerson, L. L. Coppinger, and S. C. Glazier.

1968. Ecological chemistry and the palatability spectrum. Science 161: 1349-1352.

Brower, L. P., P. B. McEvoy, K. L. Williamson, and M. A. Flannery.

1972. Variation in cardiac glycoside content of monarch butterflies from natural populations in Eastern North America. Science 117: 426-428.

Codx, M. L.

1966. A general theory of clutch size. Evolution 20: 174-184.

DADD, R. H.

1961. The nutritional requirements of locusts. V. Observations on essential fatty acids, chlorophyll, nutritional salt mixtures and the protein or amino acid components of synthetic diets. J. Insect Physiol. 6: 126-145.

1973. Insect nutrition: Current developments and metabolic implications. Ann. Rev. Entomol. $18: 381-420$.

DUFFEY, S. S.

1970. Cardiac glycosides and distastefulness: some observations on palatability spectrum of butterflies. Science 169: 78-79.

DuffeY, S. S., and G. G. E. Scudder.

1972. Cardiac glycosides in North American Asclepiadaceae, a basis for unpalatability in brightly colored Hemiptera and Coleoptera. J. Insect Physiol. 18 : 63-78.

Eggermann, W., and J. Bongers

1972. Die Wirtswahl von Oncopeltus fasciatus Dall. (Heteroptera: Lygaeidae): Bindung an Asciepiadaceen durch wirtsspezifische Glykoside. Oecologia (Berl.) 9:363-370.

EnglemanN, M. D.

1966. Energetics, terrestrial field studies, and animal productivity. IN: Advances in Ecological Research. ed. J. B. Cragg. Academic Press, London and New York. Vol. 3, pp. 73-115. 
Euw, J. V., L. Fishelson, J. A. Parsons, T. Reichstein, and M. Rothschild.

1967. Cardenolides (heart poisons) in a grasshopper feeding on milkweeds. Nature 214: 35-39.

Feir, D., and J. S. Suen.

1971. Cardenolides in the milkweed plant and feeding by the milkweed bug. Ann. ent. Soc. Amer. 64: 1173-1174.

Hansen, A. A.

1924. The poison plant situation in Indiana. J. Amer. Vet. Med. Assoc. 66: 351 .

Heal, R. E., E. F. Rogers, R. T. Wallace, and O. Starnes.

1950. A survey of plants for insecticidal activity. Lloydia 13:89-162.

Hiratsuka, E.

1920. Researches on the nutrition of the silkworm. Ball. ser. Exp. Sta. Japan, 1: 257-315.

House, H. L.

1959. Nutrition of the parasitoid Pseudosarcophaga affinis (Fall.) and of other insects. Ann. N.Y. Acad. Sci. 77: 394-405.

1961. Insect nutrition. Annu. Rev. Entomol. 6: 13-26.

1962. Insect nutrition. Annu. Rev. Biochem. 31:653-672.

1965. Effects of low levels of the nutrient content of a food and of nutrient imbalance on the feeding and the nutrition of a phytophagous larva, Celero euphorbiae (L.) (Lepidoptera: Sphingidae). Can. Ent. 97: 62-68.

Kozlovsky, D. G.

1968. A critical evaluation of the trophic level concept. I. Ecological efficiencies. Ecology 49: 48-60.

Kupchan, S. M., J. R. Knox, J. E. Kelsey, and J. A. Saenz Renauld.

1964. Calotropin, a cytotoxic principle isolated from Asclepias curassavica L. Science 1.46: 1685-1686.

LAFON, M.

1951. Quelques documents sur l'appetit et la consommation alimentaire chez les insectes. Ann. Nutr., Paris, 5 : 485-504.

LiNDEMAN, R. L.

1942. The trophic-dynamic aspect of ecology. Ecology 23: 399-418.

McGinnis, A. J., and R. Kasting.

1966. Comparison of tissues from solid- and hollow-stemmed spring wheats during growth. IV. Apparent dry matter utilization and nitrogen balance in the two-striped grasshopper, Melanoplus bivittatus (Say). J. Insect Physiol. 12: 671-678.

Odum, E. P.

1971. Fundamentals of ecology. W. B. Saunders Company, Philadelphia, Pennsylvania. 3rd edition, 574 p.

Phillipson, J.

1964. A miniature bomb calorimeter for small biological samples. Oikos 15: 130-139.

1966. Ecological energetics. William Clowes and Sons Ltd., London. $57 \mathrm{p}$.

Reynard, G. B., and J. B. S. Norton.

1942. Poisonous plants of Maryland in relation to livestock. Maryland Agr. Exp. Sta. Tech. Bull. A 10. 
Scudder, G. G. E., and S. S. Duffey.

1972. Cardiac glycosides in the Lygaeinae (Hemiptera: Lygaeidae). Can. J. Zool. $50: 35-42$.

Singh, B. and R. P. Rastogi.

1970. Cardenolides - Glycosides and Genins. Phytochemistry 9: 315-331. SooHoo, C. F. and G. Fraen Kel.

1966. The consumption, digestion, and utilization of food plants by a polyphagous insect, Prodenia eridania (Cramer). J. Insect Physiol. 12: 711-730.

VANDERZANT, E. S.

1958. The amino acid requirements of the pink bollworm. J. econ. Ent. 51: $309-311$.

WALdBauer, G. P.

1960. Feeding and growth on solanaceous and non-solanaceous plants by normal and maxillectomized larvae of the tobacco hornworm, Protoparce sexta (Johan.) (Lepidoptera: Sphingidae). Ph.D. thesis. University of Illinois, Urbana, Illinois. $134 \mathrm{p}$.

1964. The consumption, digestion, and utilization of solanaceous and non-solanaceous plants by larvae of the tobacco hornworm, Protoparce sexta (Johan.) (Lepidoptera: Sphingidae). Ent. exp. \& appl. $7: 253-269$.

1968. The consumption and utilization of food by insects. Adv. Insect Physiol. 3 : 229-282.

Williams, P. C.

1964. The colorimetric determination of total nitrogen in feeding stuffs. Analyst 89: 276-281. 

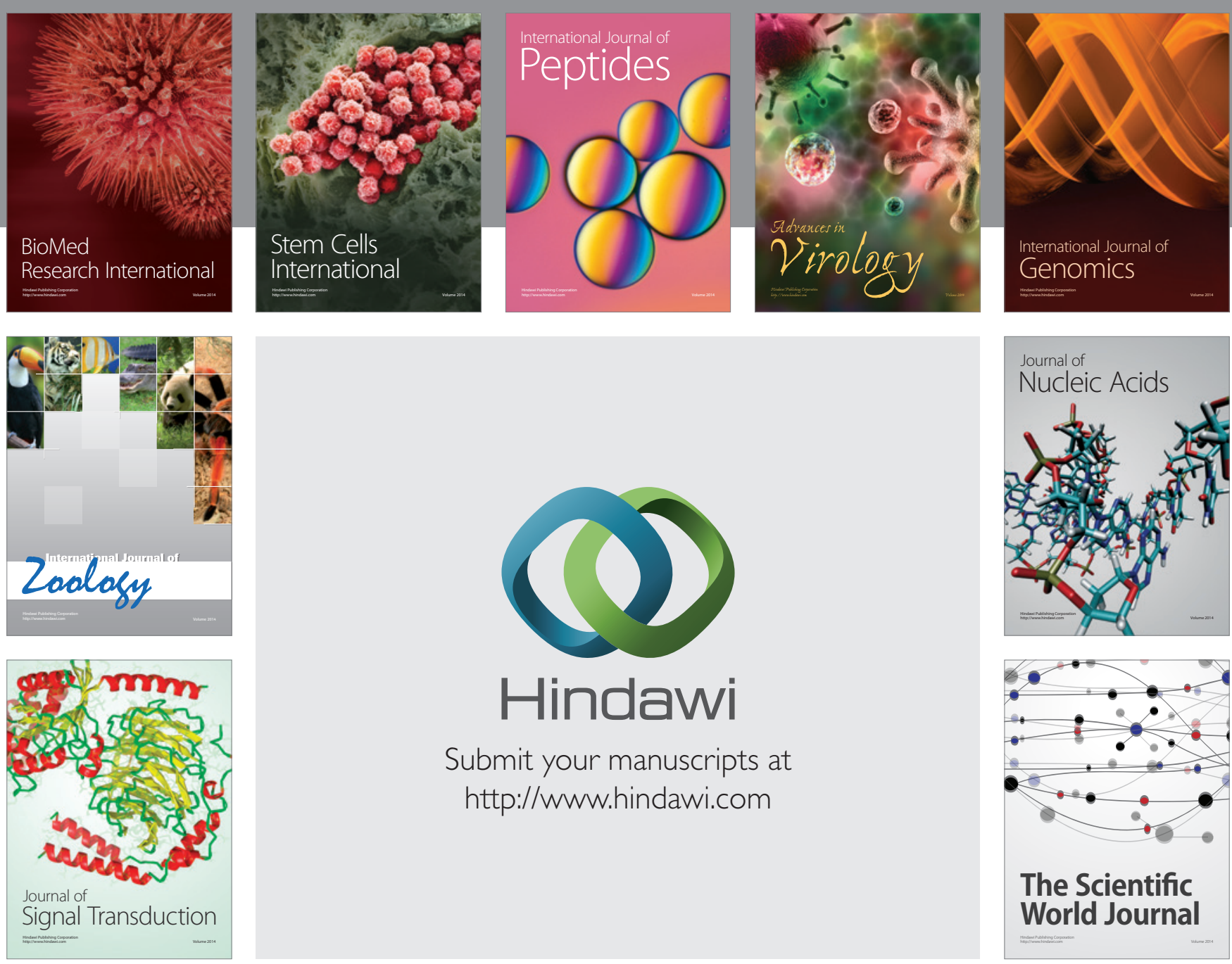

Submit your manuscripts at

http://www.hindawi.com
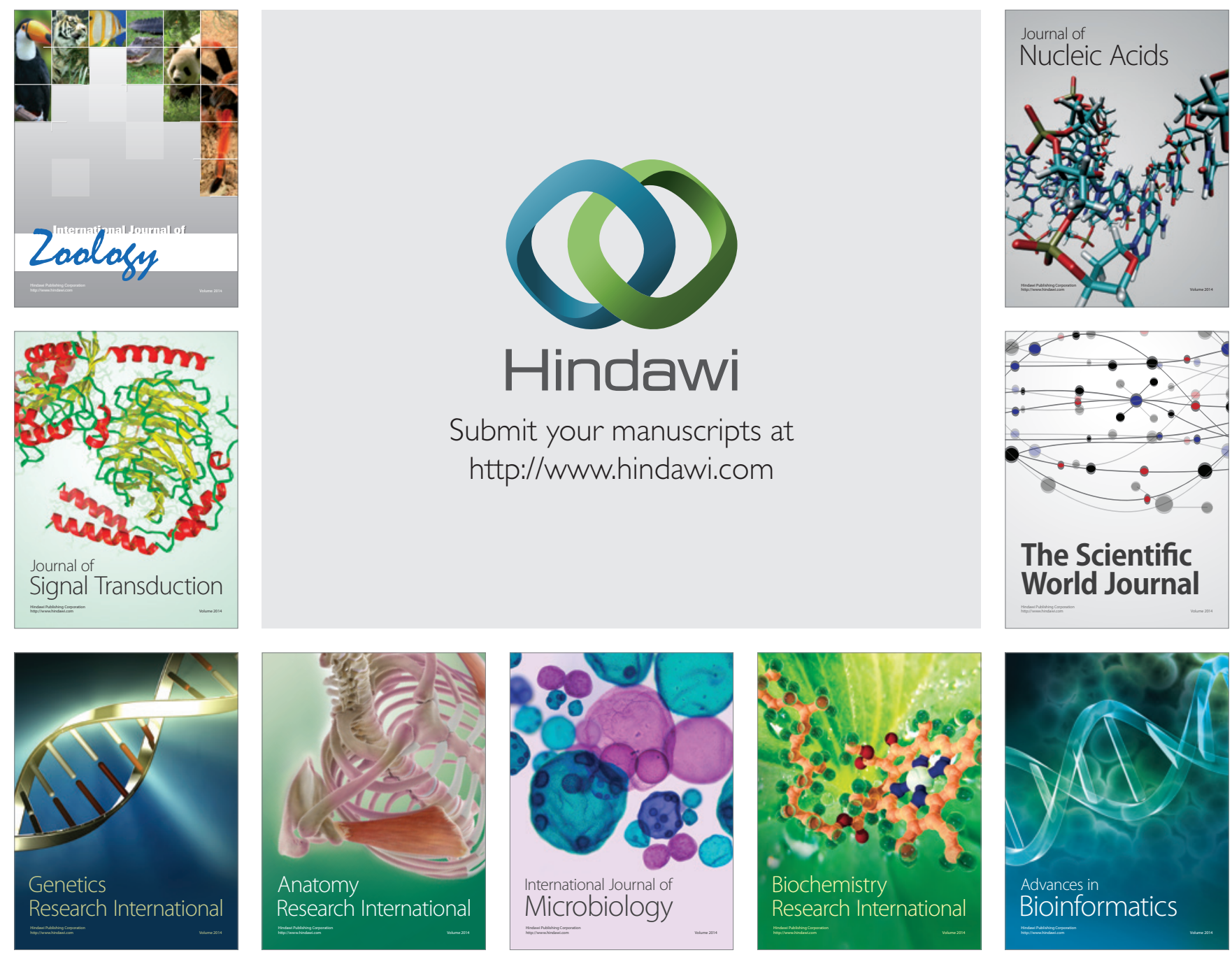

The Scientific World Journal
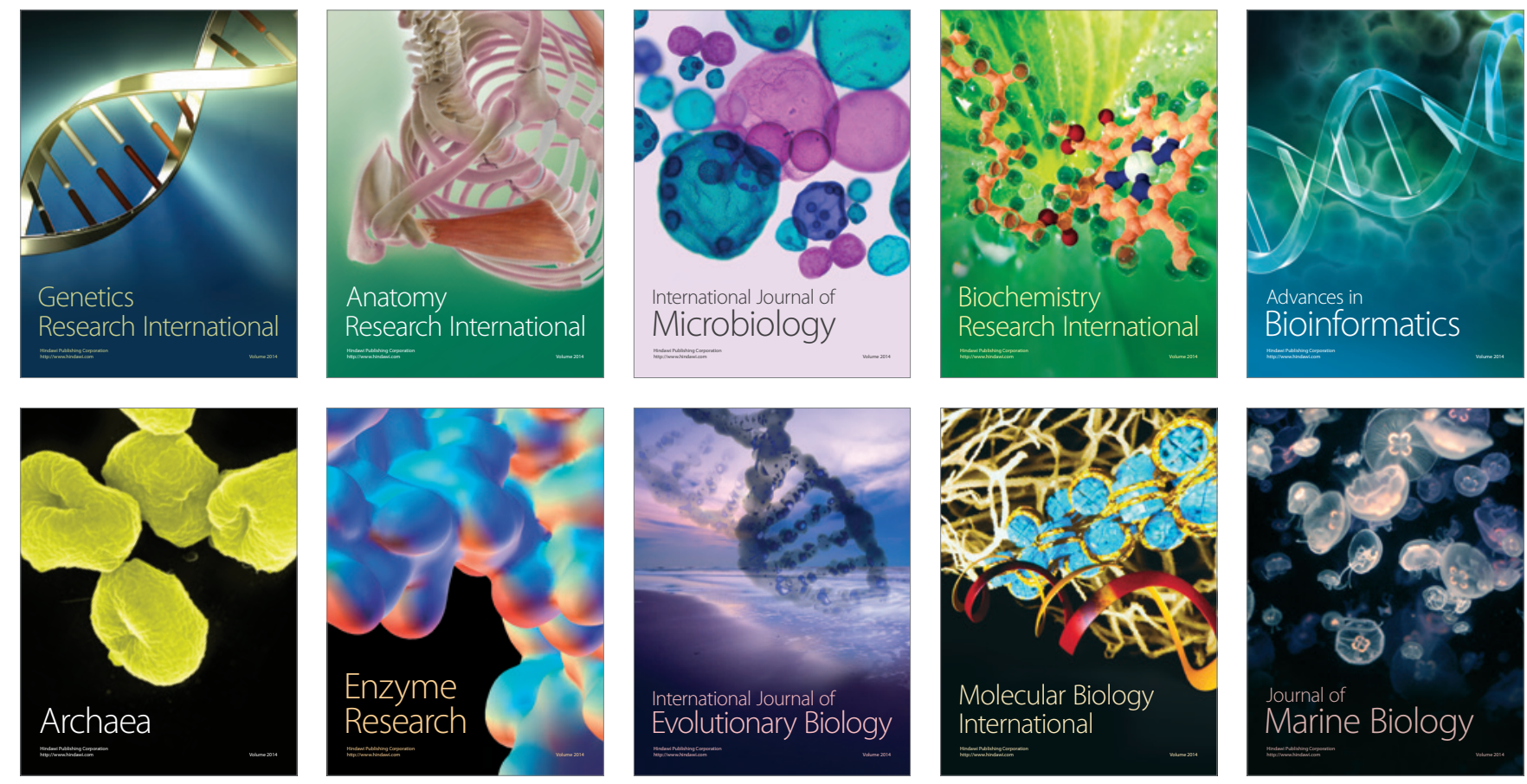